\title{
Climate change promotes parasitism in a coral symbiosis
}

\author{
David M. Baker $\mathbb{D}^{1,2,3} \cdot$ Christopher J. Freeman ${ }^{4,5} \cdot$ Jane C.Y. Wong ${ }^{1} \cdot$ Marilyn L. Fogel $^{3,6} \cdot$ Nancy Knowlton $^{2}$
}

Received: 22 May 2017 / Revised: 17 November 2017 / Accepted: 5 December 2017 / Published online: 29 January 2018

(c) The Author(s) 2018. This article is published with open access

\begin{abstract}
Coastal oceans are increasingly eutrophic, warm and acidic through the addition of anthropogenic nitrogen and carbon, respectively. Among the most sensitive taxa to these changes are scleractinian corals, which engineer the most biodiverse ecosystems on Earth. Corals' sensitivity is a consequence of their evolutionary investment in symbiosis with the dinoflagellate alga, Symbiodinium. Together, the coral holobiont has dominated oligotrophic tropical marine habitats. However, warming destabilizes this association and reduces coral fitness. It has been theorized that, when reefs become warm and eutrophic, mutualistic Symbiodinium sequester more resources for their own growth, thus parasitizing their hosts of nutrition. Here, we tested the hypothesis that sub-bleaching temperature and excess nitrogen promotes symbiont parasitism by measuring respiration (costs) and the assimilation and translocation of both carbon (energy) and nitrogen (growth; both benefits) within Orbicella faveolata hosting one of two Symbiodinium phylotypes using a dual stable isotope tracer incubation at ambient $\left(26^{\circ} \mathrm{C}\right)$ and sub-bleaching $\left(31^{\circ} \mathrm{C}\right)$ temperatures under elevated nitrate. Warming to $31^{\circ} \mathrm{C}$ reduced holobiont net primary productivity (NPP) by $60 \%$ due to increased respiration which decreased host \%carbon by $15 \%$ with no apparent cost to the symbiont. Concurrently, Symbiodinium carbon and nitrogen assimilation increased by 14 and $32 \%$, respectively while increasing their mitotic index by $15 \%$, whereas hosts did not gain a proportional increase in translocated photosynthates. We conclude that the disparity in benefits and costs to both partners is evidence of symbiont parasitism in the coral symbiosis and has major implications for the resilience of coral reefs under threat of global change.
\end{abstract}

Electronic supplementary material The online version of this article (https://doi.org/10.1038/s41396-018-0046-8) contains supplementary material, which is available to authorized users.

David M. Baker

dmbaker@hku.hk

1 School of Biological Sciences, Swire Institute of Marine Science, The University of Hong Kong, Pokfulam Rd., Hong Kong, PR China

2 National Museum of Natural History, Smithsonian Institution, 1000 Constitution Ave., NW, Washington, DC 20560, USA

3 Geophysical Laboratory, Carnegie Institution of Washington, 5200 Broad Branch Rd., NW, Washington, DC 20015, USA

4 Department of Biology, University of Alabama at Birmingham, Birmingham, AL, USA

5 Smithsonian Marine Station, Ft. Pierce, FL, USA

6 Department of Earth Sciences, University of California, Riverside, CA, USA

\section{Introduction}

Animal-microbe symbioses are common in the ocean, and are often associated with extreme environmental biogeochemistry. For example, deep-sea tubeworms host microbial symbionts that are capable of generating energy and biomass via chemoautotrophy of rich inorganic mineral substrates in the complete absence of sunlight. Conversely, sunlight is abundant in the shallow tropical oceans, while inorganic nutrients are limiting to ecosystem productivity. Therefore, partnerships between animals and autotrophic microbes like cyanobacteria and protists confers the host with the ability to harness light energy and transform myriad forms of nitrogen into the building blocks for important biomolecules like enzymes, proteins, and nucleic acids [1]. Through symbiosis, benthic animals such as sponges and corals have become some of the most successful competitors for space in the tropical seas.

However, the conditions under which such symbioses evolved are rapidly changing in the Anthropocene [2]. The coral symbiosis, like many obligate symbiotic associations, is sensitive to environmental change. Rising sea surface 
temperatures have a direct impact on coral respiration and energy budgets. Coastal eutrophication is worsening which acts synergistically with thermal stress to exacerbate coral bleaching and alters the competitive advantages corals' nutritional symbioses convey [3]. As a consequence, reefs are experiencing a perilous global decline which may be irreversible [2, 4]. Under such conditions it has been increasingly suggested that the myriad species of coralhosted Symbiodinium can be placed along a continuum from mutualist to parasite, with the latter implying that the symbionts parasitize their host of resources and reduce host fitness [5, 6]. Indeed, several examples of this have been documented for stress-tolerant lineages of Symbiodinium, including phylotypes from the A and D ITS2 clades. However, evidence of parasitism and cheating in the coral nutritional symbiosis is sparse with the best examples revealing long-term reductions in host fitness associated with certain Symbiodinium types [5-8].

Nutritional exchanges are critical to understanding the performance of a symbiosis under stress. For corals, there are two simplified perspectives on the relative importance of mechanisms within the holobiont that underpin and precede the bleaching response. A "host-centered" perspective reveals that host species' capacity for heterotrophy and lipid storage confers thermal tolerance, bleaching resistance, and post-bleaching resilience [9]. In sum, hosts that can store more energy and/or obtain nutrition from heterotrophic sources during thermal stress are more likely to survive bleaching events. A second perspective is "symbiont-centered" and is based on thermal stress impairing photosynthetic performance of Symbiodinium by damaging the photosynthetic architecture including the thylakoid membrane $[10,11]$. When combined with Symbiodinium's propensity for photorespiration [12], damaged membranes produce reactive oxygen species [13] that induce host apoptosis, immune responses and ultimately, symbiont expulsion. However, some Symbiodinium tolerate temperatures exceeding $34^{\circ} \mathrm{C}$ in hospite or even after expulsion (far higher than most corals' bleaching threshold) and exhibit enhanced growth rates [14, 15]. These exceptional observations challenge the theory that Symbiodinium are universally impaired at high temperatures and suggest that other factors in addition to photodamage are involved in the bleaching outcome.

Wooldridge [16] presented an integrative model for the breakdown of the coral symbiosis, detailing how mutualistic symbionts might shift to parasitism in the warming period preceding bleaching [16]. The model is based on the need for the coral host to supply exogenous carbon for Symbiodinium photosynthesis. Although $\mathrm{CO}_{2}$ can be sourced from host respiration of heterotrophic substrates, in many species the abundant ATP derived from photosynthesis is sufficient to sustain a positive feedback on the activity of carbonic anhydrase, which converts seawater bicarbonate into intracellular $\mathrm{CO}_{2}$. The diversity of active carbon concentrating mechanisms found in corals highlights the importance of this feedback [17]. Provided that symbiont growth is limited by lack of nutrients, cell division is minimized and hosts can accumulate translocated photosynthates as energy reserves to maintain symbiotic homeostasis. However, chronic metabolic imbalances caused by environmental perturbation, particularly eutrophication, but also high $p \mathrm{CO}_{2}$ and irradiance favor the proliferation of Symbiodinium within the host [18, 29]; Fagoonee 1999). As such, Symbiodinium are predicted to retain more carbon (as molecular skeletons for amino and nucleic acids) in order to sequester more nitrogen for cell division [19]. Thus, the flow of energy to the host is lessened, forcing increased respiration of lipid reserves to maintain metabolic functioning.

At this point, host investments in supplying exogenous $\mathrm{CO}_{2}$ for photosynthesis no longer yield returns as the flow of carbon ends in the Symbiodinium sink. Consequently, the likelihood of bleaching increases as a result of a weakened host unable to tolerate the burgeoning symbiont population which becomes primed for bleaching when temperature and irradiance are high [13, 20-22]. As such, there is a presumption that the mutualistic symbiont has become more parasitic by "cheating" the host of resource subsidies while reducing host fitness. The transition from symbiont to parasite can be defined by increasing costs that exceed benefits gained by the host [23, 24] and may be more evident in phylotypes that demonstrate "cheating" behaviors. Indeed, Lesser et al. [5] suggested that cheating in corals is evidenced by the observation of the temporary dominance of "infectious" and opportunistic Symbiodinium species such as $S$. trenchii. The competitive displacement and/or hostmodulated winnowing of "inferior" symbionts further suggests that the host can influence this process, perhaps by optimizing subsidies for mutualists or implementing sanctions on parasites [49] (McIlroy \& Coffroth 2017). These processes are thought to be mediated by symbiont competition, which is predicted to vary with environmental factors such as heat, light, and nutrient stress [25, 26]. However, many of these theoretical processes lack empirical data for corals.

The importance of filling this gap is urgent given that synergistic effects of temperature and nutrient stress reduce coral reef resilience. Wooldridge and Done (2009) showed that on Australia's Great Barrier Reef, nearshore coral reefs exposed to chronic terrestrial nitrogen pollution bleached at temperatures $2{ }^{\circ} \mathrm{C}$ lower than offshore oligotrophic reefs. This finding implies that management policies aimed at reducing the future risk of coral bleaching need to consider both "local" nutrient pollution and "global" climate change minimization strategies [27]. 
In addition to this correlative field observation, a recently developed theoretical biogenergetic simulation model [28] was found to support the mechanistic bleaching predictions of the Wooldridge model. However, targeted experimental studies that directly test/validate the Wooldridge model are currently lacking. Only indirect observations are available for discrimination. For example, at the "front end" of the model, studies have shown that Symbiodinium growth is stimulated by exogenous nitrogen $[29,30]$. At the "back end" of the model, studies have confirmed that nitrogen has a direct effect on coral health [11,31,32], and that a large symbiont burden can make corals more vulnerable to bleaching and disease [3, 18]. Together, these bodies of evidence suggest that symbiont benefits are not synonymous with host benefits and that parity is lost under times of stress; an indication of the unsustainable cost of symbiosis. Yet, none of these studies have examined the capacity for symbionts to cheat or parasitize their hosts which requires a focus on metabolism and nutrient assimilation and translocation during periods of stress. Here we ask the question, do Symbiodinium become parasites at elevated temperatures?

\section{Methods}

\section{Field collections}

In November 2011, small pieces from apparently healthy colonies of Orbicella faveolata were sampled from 2 locations near Carrie Bow Cay, Belize using a hammer and chisel. First, colonies from the shallow backreef area of Curlew Reef $\left(16^{\circ} 47^{\prime} 24.14^{\prime \prime} \mathrm{N}, 8^{\circ} 4^{\prime} 46.94^{\prime \prime} \mathrm{W}\right)$ were sampled from 1-3 m depth $(n=10)$. These colonies exhibited a greenish-brown pigmentation. Subsequently, samples from the deeper forereef on the windward side of the Smithsonian field station $\left(16^{\circ} 48^{\prime} 20.87^{\prime \prime} \mathrm{N}, 88^{\circ} 4^{\prime} 40.46^{\prime \prime} \mathrm{W}\right)$ were sampled down to the lower limit of the species distribution at $\sim 15 \mathrm{~m}$ $(n=10)$. These colonies were distinctly gray-brown in appearance. Colonies exhibiting any sign of compromised health were excluded from sampling. All fragments were immediately transported to the Smithsonian field station in buckets of seawater, and fragmented into 3 equally sized pieces of $\sim 4 \mathrm{~cm}^{2}$. One fragment was immediately frozen as an initial baseline sample. The remaining two clonal fragments were separated into two temperature treatments.

\section{Temperature incubation}

The first treatment was an ambient temperature flowthrough seawater tank that had an average temperature of $26^{\circ} \mathrm{C}$. The second treatment was similar in all aspects except it was gradually warmed to $31{ }^{\circ} \mathrm{C}$ at a rate of $0.6{ }^{\circ} \mathrm{C}$ per day over the course of 8 days using $500 \mathrm{~W}$ titanium heaters with thermostats. This temperature and rate of warming was chosen based on records of bleaching from corals in Belize [33]. Both treatments were positioned in partial shade outdoors with flowing seawater with equal rates of exchange $\left(\sim 1 \mathrm{~L} \mathrm{~min}^{-1}\right)$. Water was sourced from the leeward side of the island, pumped to a settlement tank, and then gravity fed to the treatment tanks. Owing to lack of electricity, heaters were powered by a GoalZero lead-acid battery system at night. Temperature and light were logged during each experiment at $10 \mathrm{~min}$ intervals using a HOBO Pendant (Onset, Bourne, MA). A logger was deployed inside a bottle as well as outside of the tank to account for variations associated with internal bottle conditions. Once the target temperature was reached and maintained for $24 \mathrm{~h}$, the tracer experiment was initiated. During the incubation, temperature averaged $24.5-25.6{ }^{\circ} \mathrm{C}$ and $29.6-30.6{ }^{\circ} \mathrm{C}$ in the ambient and heated treatment, respectively. Illumination within the bottles averaged 310 to $510 \mu \mathrm{mol}$ quanta $\mathrm{m}^{-2} \mathrm{~s}^{-1}$ PAR, which is equivalent to in situ conditions from 8-25 m depth on the forereef [34].

\section{Stable isotope tracer experiment}

At the end of the temperature incubation, clonal pairs of half of the sampled corals ( $n=5$ shallow, 5 deep) were haphazardly chosen and each clonal fragment was placed independently into an opaque $500 \mathrm{~mL}$ wide-mouth Nalgene bottle ( $\sim 50 \%$ light transmission). At sunrise, each bottle was filled completely with $0.7 \mu \mathrm{M}$ filtered seawater (FSW) labeled with $\mathrm{Na}^{15} \mathrm{NO}_{3}$ and $\mathrm{NaH}^{13} \mathrm{CO}_{3}$ to non-limiting concentrations ( $\sim 3 \mu \mathrm{M}$ and $2.2 \mathrm{mM}$, respectively). Nitrate was chosen as a nitrogen source to track autotrophic assimilation as only Symbiodinium express nitrate reductase [26]. Care was given to minimize the amount of air trapped in the bottle. After recording dissolved oxygen (DO; $\mathrm{mg} \mathrm{L}^{-1}$ ) using a Nexsens $\mathrm{O}_{2}$ electrode, the bottles were sealed tightly and positioned haphazardly in the respective water bath in an upright position, ensuring that the coral fragment was also facing upwards. After $9.8 \mathrm{~h}$ of incubation, bottles were opened and a second DO measurement was made before removing samples from the bottles and rinsing them with copious amounts of flowing seawater for $\sim 10 \mathrm{~min}$, in an effort to flush away any unassimilated inorganic tracers. Each fragment was quickly rinsed in deionized water, and frozen overnight. The next day, the experiment was repeated with the remaining clones beginning $20 \mathrm{~min}$ earlier and for the same duration. There was no effect of the day of experimentation on the results so all the resulting data were pooled for analysis. Approximately $3 \mathrm{~mL}$ of seawater was retained from each bottle and frozen for $\left[\mathrm{NO}_{3}{ }^{-}\right]$determination using the cadmium reduction method using a colorimetric test kit (Lamotte). 


\section{Sample processing}

After freezing, each sample was removed and photographed. The host tissues and Symbiodinium were removed under a stream of deionized water using an airbrush powered by a SCUBA tank. Deionized water was chosen as a medium as it contains no confounding sources of carbon or nitrogen. The volume of blastate generated by airbrushing was noted, and the liquid was homogenized further using a tissue homogenizer. Three, $1 \mathrm{~mL}$ aliquots of this homogenate were transferred to microcentrifuge tubes for subsequent measurements, which included the following; (1) quantification of Symbiodinium cell density, (2) chlorophyll a concentration [chla], and (3) separation of host and symbiont fractions for Symbiodinium ITS2 genotyping and stable isotope analysis. The surface area $\left(\mathrm{cm}^{2}\right)$ of each fragment was estimated from image analysis using ImageJ software (NIH). A $1 \mathrm{~mL}$ aliquot of homogenate from each sample was centrifuged to separate and clean the symbiont cells from the host tissues. A drop of Lugol's iodine was added to facilitate visualization of cells. Cell counts were taken using a Bright-Line hemocytometer under a light microscope at $10 \times$ magnification, and cell densities (cells $\mathrm{cm}^{-2}$ ) were determined from the average of duplicate cell counts. [chla] was determined following extraction in $90 \%$ acetone and measuring the absorbance of the extract at 647 and $664 \mathrm{~nm}$ following the equations of Jeffrey and Humphrey [35].

\section{Symbiont identity \& Mitotic Index}

We identified the dominant Symbiodinium genotype present in our samples using direct sequencing of the ITS2 region of the nrDNA. Total genomic DNA was extracted from frozen Symbiodinium pellets using a MoBio PowerSoil DNA extraction kit. The PCR followed the ITS2 "touchdown" protocol developed by LaJeunesse [36]. Details of postPCR cleanup, and Sanger sequencing are detailed in Baker et al. [26]. Forward and reverse sequences were aligned and trimmed using Geneious 6.0 (Biomatters Ltd). Consensus sequences were used for BLAST searches to identify the closest match in NCBI GenBank. Sequences were crossreferenced with the GeoSymbio database [37].

A second aliquot of the frozen cell suspension was loaded into a hemocytometer to count the total number of dividing Symbiodinium cells (doublets) relative to the total number of cells using a fluorescent microscope (80i, Nikon, Tokyo, Japan). Mitotic index (MI) was calculated as the quotient of the two measures, respectively. A total of 9426 individual cell observations were recorded across all samples from the post-incubation sampling. These data were used to simulate growth projections beyond the duration of the experiment (Supplemental Materials).

\section{Stable isotope analysis}

Frozen host and symbiont fractions were lyophilized, weighed into $4 \times 6 \mathrm{~mm} \mathrm{Ag}$ capsules and treated with $\sim 10$ $\mu \mathrm{L}$ of $6 \mathrm{~N}$ constant-boiling $\mathrm{HCl}$ (Pierce) to remove inorganic carbonates. The acid was evaporated in a hood for several hours and then dried overnight in an oven at $60^{\circ} \mathrm{C}$. Each capsule was rolled and combusted in a Carlo-Erba NC2500 Elemental Analyzer coupled to a Thermo Delta V isotope ratio mass spectrometer via a Conflo III open-split interface to measure $\delta^{15} \mathrm{~N}, \delta^{13} \mathrm{C}$ and the $\% \mathrm{~N}$ and $\% \mathrm{C}$ of each sample. Samples were analyzed in separate runs, in order of anticipated enrichment (initials $>$ host $>$ symbiont). Analytical precision was determined using an in-house acetanilide standard (ACET; 70\%C, 10\%N). Precision of initials (nat. abundance) was less than \pm 0.1 and $0.2 \%$ for $\delta^{15} \mathrm{~N}$ and $\delta^{13} \mathrm{C}$, respectively. Precision of standards measured with enriched samples was \pm 4.5 and $1.4 \%$, respectively. Enriched values are reported as atom\% of the heavy isotope $\left(\mathrm{AP}^{15} \mathrm{~N} \&\right.$ $\mathrm{AP}^{13} \mathrm{C}$ ), which is calculated by the count of the heavy isotope relative to the total number of atoms of $\mathrm{N}$ or $\mathrm{C}$ in the sample.

\section{Data analyses}

All measured parameters were screened for normality and homoscedasticity using Shapiro-Wilk and Levene's test, respectively. Differences in coral physiology (Symbiodinium density, [chla], NPP, and C:N) were determined by ANOVA followed by pairwise post hoc Student's $t$ tests. We tested for the effect of depth and temperature on $\mathrm{AP}^{15} \mathrm{~N}$ and $\mathrm{AP}^{13} \mathrm{C}$ using a Standard Least Squares (SLS) model, where differences between groups were assessed from the interaction term (depth $\times$ temperature) using post hoc Student's $t$ tests on the Least Squares means. The difference between symbiont and host $\mathrm{AP}^{15} \mathrm{~N}$ and $\mathrm{AP}^{13} \mathrm{C}$ (e.g., $\Delta \mathrm{AP}^{15} \mathrm{~N}_{\text {symbiont-host }}$ ) was determined using Student's $t$ tests.

\section{Results}

\section{O. faveolata physiology}

Shallow collected colonies of $O$. faveolata had approximately double the Symbiodinium densities of their deeper conspecifics (two-tailed $t$ test, $p<0.01$; Table 1). The average chlorophyll content per sample was slightly, but not significantly, higher in shallow colonies. However, when normalized for Symbiodinium densities, there was no difference in the chla per cell between either group of $O$. faveolata (Table 1). The net primary productivity (NPP; $\Delta \mathrm{DO})$ was similar for shallow and deep holobionts; however, NPP among all holobionts was significantly reduced at 
high temperature (ANOVA; $F_{3,40}=13.72, p<0.0001$ ). There was $60 \%$ more DO generated at $26{ }^{\circ} \mathrm{C}$ than at $31{ }^{\circ} \mathrm{C}$ (mean $\mathrm{mg} \mathrm{L}^{-} 1 \pm$ s.e.m.; $7.65 \pm 0.3$ and $4.66 \pm 0.3$, respectively). Overall, $>50 \%$ of $\mathrm{NO}_{3}{ }^{-}$was removed during the incubation, decreasing from $\sim 2.5 \mu \mathrm{M}$ to $1.0 \mu \mathrm{M}$. However, there was no effect of temperature, depth, or the interaction term temperature $\times$ depth on the final $\left[\mathrm{NO}_{3}{ }^{-}\right]\left(\mathrm{SLS} ; R^{2}=\right.$ $0.09 ; F=1.17 ; p=0.33)$, suggesting that the $\left[\mathrm{NO}_{3}{ }^{-}\right]$ measurements were too coarse to determine uptake via substrate removal from the media. C:N varied significantly with depth and coral fraction (ANOVA; $F_{3,20}=19.8, p<$ 0.001). Shallow Symbiodinium C:N (mean \pm s.e.m $=6.8 \pm$ $0.1)$ was significantly higher than deep Symbiodinium and their hosts $(6.3 \pm 0.1$ and $6.1 \pm 0.1$, respectively), which were significantly higher than shallow hosts $(5.7 \pm 0.1$; post hoc Student's $t$, all $p<0.02$ ). Following the 10 day temperature incubation, host tissue $\% \mathrm{C}$ content decreased by $15 \%$ (from mean $=3.6 \pm 0.2$ to $3.06 \% \pm 0.2$ ) across depth/ clade (ANOVA; $F_{3,20}=4.96, p=0.03$ ), whereas Symbiodinium \%C content was unchanged. At the same time, Symbiodinium mitotic index increased from $6.4 \pm$ 0.3 to $7.4 \% \pm 0.3$ across depth/clade $(t$ (two- tailed $)=2.18$; $p=0.043)$; a $15.9 \%$ increase in MI.

\section{Symbiodinium ITS2}

Eight out of 10 Symbiodinium samples were successfully identified to ITS2 phylotype from the shallow and deep samples $(n=16 / 20)$. All shallow colonies were found to host Symbiodinium fitti (ITS2 phylotype A3) with $>95 \%$ pairwise identity matching to the GeoSymbio reference sequence [37]. All deep Symbiodinium matched the undescribed ITS2 phylotype C7 with $>98 \%$ pairwise identity matching to the GeoSymbio reference sequence. One deep sample was ambiguous and repeated sequencing attempts revealed dominance by either $\mathrm{A} 3$ or $\mathrm{C} 1$ with $100 \%$ pairwise identity matching to either reference sequence. As the majority of samples were partitioned evenly by depth and clade, the relative contribution of those categories on metabolic performance were not deemed mutually exclusive. Therefore, we combined these data by depth/clade for subsequent evaluation of temperature effects on the two $O$. faveolata S. fitti / ITS2 phylotype C holobionts. All Symbiodinium sequences were archived in GenBank (accession numbers MF471328-MF471343).

\section{${ }^{13} \mathrm{C}$ assimilation}

All Symbiodinium assimilated significant quantities of ${ }^{13} \mathrm{C}$, increasing from 1.1 (natural abundance) to $>2.0 \mathrm{AP}^{13} \mathrm{C}$ symbiont $\left(\delta^{13} \mathrm{C}\right.$ increasing from -13.0 to $>782 \%$; Table 2$)$. Host tissues were less enriched but still attained a minimum of $1.4 \mathrm{AP}^{13} \mathrm{C}_{\text {host }}\left(\delta^{13} \mathrm{C}>312 \%\right.$ o). Deep/C7 holobionts fixed 
Table 2 Mean ( \pm s.e.) natural abundance isotope values (in delta notation) and \% carbon content from initial fragments of Orbicella faveolata and their Symbiodinium collected from the deep and shallow forereef of Carrie Bow Caye, Belize (top) and the enriched atom \% heavy isotope values, $\% \mathrm{C}$, and mitotic index of experimental samples following a $9.8 \mathrm{~h}$ incubation in ${ }^{15} \mathrm{NO}_{3}{ }^{-}$and $\mathrm{H}^{13} \mathrm{CO}_{3}{ }^{-}$after 10 days of acclimation to an ambient $\left(26^{\circ} \mathrm{C}\right)$ and elevated $\left(31^{\circ} \mathrm{C}\right)$ temperature

\begin{tabular}{llllllllll}
\hline Treatment (nat. abs.) & Origin & $\mathrm{n}$ & $\delta^{15} \mathrm{~N}_{\text {host }}(\%)$ & $\delta^{15} \mathrm{~N}_{\text {symbiont }}(\%)$ & $\delta^{13} \mathrm{C}_{\text {host }}(\%)$ & $\delta^{13} \mathrm{C}_{\text {symbiont }}(\%)$ & $\% \mathrm{C}_{\text {host }}$ & $\% \mathrm{C}_{\text {symbiont }}$ & $\mathrm{MI}(\%)$ \\
\hline Initial & DEEP & 9 & $2.2 \pm 0.1$ & $0.5 \pm 0.2$ & $-13.1 \pm 0.2$ & $-13.2 \pm 0.2$ & $4.1 \pm 1.1$ & $37.7 \pm 1.1$ & n.a. \\
& SHALLOW & 10 & $3.9 \pm 0.4$ & $1.6 \pm 0.1$ & $-11.5 \pm 0.3$ & $-12.0 \pm 0.4$ & & \\
Treatment (enriched) & Origin & $n$ & $\mathrm{AP}^{15} \mathrm{~N}_{\text {host }}$ & $\mathrm{AP}^{15} \mathrm{~N}_{\text {symbiont }}$ & $\mathrm{AP}^{13} \mathrm{C}_{\text {host }}$ & $\mathrm{AP}^{13} \mathrm{C}_{\text {symbiont }}$ & $\% \mathrm{C}_{\text {host }}$ & $\% \mathrm{C}_{\text {symbiont }}$ & $\mathrm{MI}_{(\%)}$ \\
$26^{\circ} \mathrm{C}$ & DEEP & 10 & $0.78 \pm 0.03^{\dagger}$ & $1.33 \pm 0.08^{\mathrm{a}}$ & $1.74 \pm 0.04^{\mathrm{a}}$ & $3.24 \pm 0.08^{\mathrm{a}}$ & $3.6 \pm 0.2$ & $42.7 \pm 1.6$ & $6.4 \pm 0.3$ \\
& SHALLOW & 10 & $0.60 \pm 0.02$ & $0.96 \pm 0.07$ & $1.59 \pm 0.04$ & $2.42 \pm 0.10$ & & & \\
$31{ }^{\circ} \mathrm{C}$ & DEEP & 10 & $0.82 \pm 0.04^{\mathrm{a}}$ & $\mathbf{1 . 7 4} \pm \mathbf{0 . 1 5}$ & $1.76 \pm 0.04^{\mathrm{a}}$ & $3.30 \pm 0.11^{\mathrm{a}}$ & $\mathbf{3 . 0 6} \pm \mathbf{0 . 2}$ & $41.8 \pm 1.6$ & $\mathbf{7 . 4} \pm \mathbf{0 . 3}$ \\
& SHALLOW & 10 & $0.66 \pm 0.02$ & $\mathbf{1 . 2 7} \pm \mathbf{0 . 1 0}$ & $1.62 \pm 0.04$ & $\mathbf{2 . 7 6} \pm \mathbf{0 . 1 1}$ & & &
\end{tabular}

Values in "bold" indicate a significant temperature effect

indicates a significant difference between sampling depths
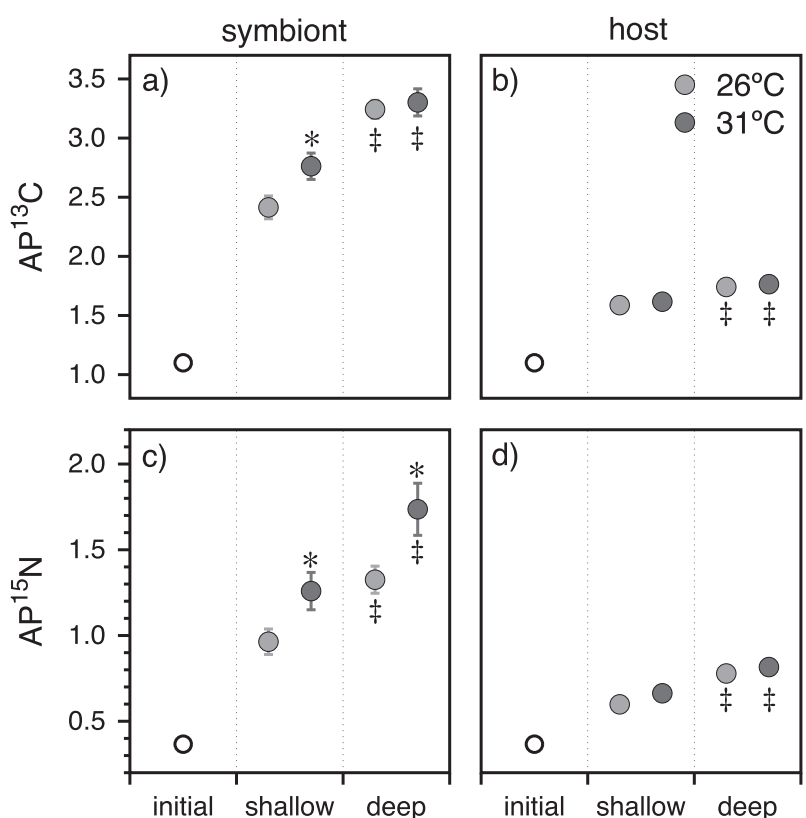

Fig. 1 Atom $\%{ }^{13} \mathrm{C}(\mathbf{a}, \mathbf{b})$ and $\%{ }^{15} \mathrm{~N}$ enrichment $(\mathbf{c}, \mathbf{d})$ of Orbicella faveolata (right) and their Symbiodinium (left) after a $10 \mathrm{~h}$ pulse of ${ }^{15} \mathrm{NO}_{3}{ }^{-}$and $\mathrm{H}^{13} \mathrm{CO}_{3}{ }^{-}$following a 10 -day incubation at ambient $\left(26^{\circ}\right.$ C) and elevated $\left(31^{\circ} \mathrm{C}\right)$ temperature. Points represent the mean $+/-$ standard error of 10 replicate samples collected from the shallow $(1 \mathrm{~m}$; dominated by ITS 2 phylotype A3) and deep ( $15 \mathrm{~m}$; dominated by ITS 2 phylotype C7) fore-reef at Carrie Bow Cay, Belize. Initial samples reflect the natural abundance isotope composition prior to tracer incubation. * indicates a significant difference between the temperature treatments within a depth fraction. $\ddagger$ indicates a significant difference between shallow and deep samples

more ${ }^{13} \mathrm{C}$ than shallow/A3 holobionts, regardless of temperature (Fig. 1a, b). There was a significant effect of depth/ clade, but not temperature on $\mathrm{AP}^{13} \mathrm{C}_{\text {host }}$ and $\mathrm{AP}^{13} \mathrm{C}_{\text {symbiont }}$ (SLS; all $p<0.0002$; Fig. 1a, b). The mean $\mathrm{AP}^{13} \mathrm{C}_{\text {symbiont }}$ from deep/C7 holobionts was up to $34 \%$ more enriched

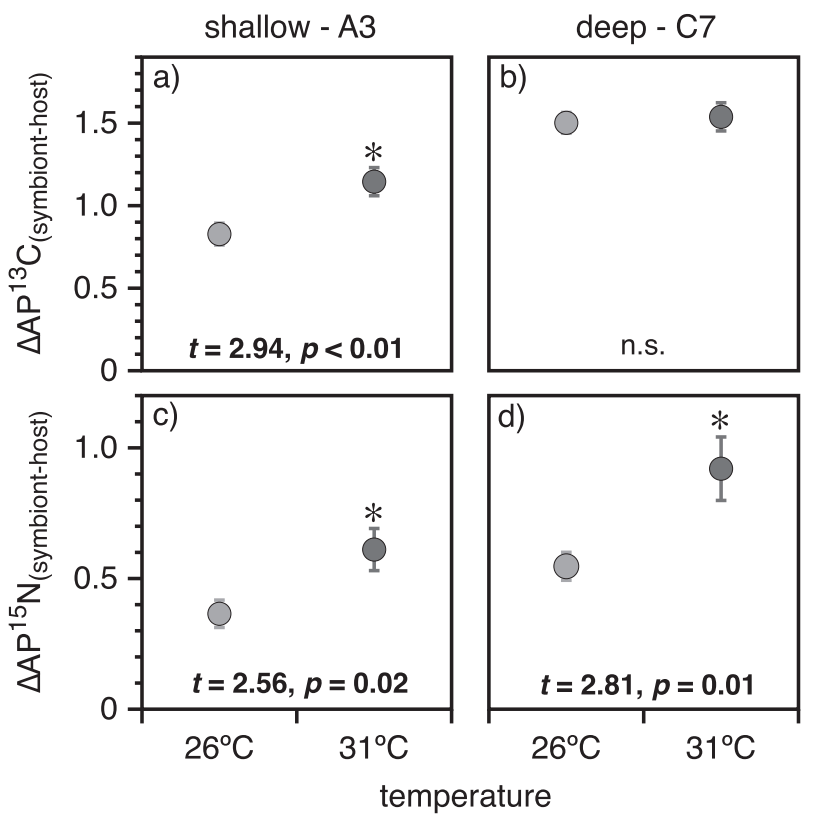

Fig. 2 The mean difference between atom \% enrichment of carbon (a, b) and nitrogen $(\mathbf{c}, \mathbf{d})$ observed between Symbiodinium and their Orbicella faveolata hosts after $10 \mathrm{~h}$ exposure to $\mathrm{H}^{13} \mathrm{CO}_{3}{ }^{-}$and ${ }^{15} \mathrm{NO}_{3}{ }^{-}$ and following a 10 day incubation at ambient $\left(26^{\circ} \mathrm{C}\right)$ and elevated $(31$ ${ }^{\circ} \mathrm{C}$ ) temperature. Points represent the mean $+/-$ standard error of 10 replicate samples collected from the shallow (1 m; dominated by ITS2 phylotype A3) and deep ( $15 \mathrm{~m}$; dominated by ITS2 phylotype C7) fore-reef at Carrie Bow Cay, Belize pooled from 2 replicated experiments. $*$ indicates a significant difference between the temperature treatments as determined by Student's $t$ test

relative to shallow/A3 holobionts (two-tailed $t=-6.7, \mathrm{~d} f$ $=36, p<0.0001$; Fig. 1a). Similarly, $\mathrm{AP}^{13} \mathrm{C}_{\text {host }}$ was $9 \%$ more enriched in the deep/C7 holobionts $(t$ (two-tailed) $=$ $-4.17, \mathrm{~d} f=36, p=0.0002$; Fig. $1 \mathrm{~b})$. There was a significant effect of temperature on $\mathrm{AP}^{13} \mathrm{C}_{\text {symbiont }}$ among the shallow/A3 corals only, which was $14 \%$ greater in the $31{ }^{\circ} \mathrm{C}$ 
treatment relative to $26^{\circ} \mathrm{C}$ (two-tailed $t=2.43, \mathrm{~d} f=36, p$

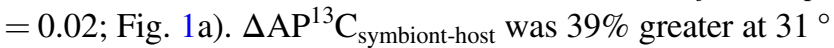
$\mathrm{C}$ than at $26^{\circ} \mathrm{C}$ for shallow/A3 but not deep/C7 $O$. faveolata (Fig. 2 a, b).

\section{${ }^{15} \mathrm{~N}$ assimilation}

All Symbiodinium assimilated significant quantities of ${ }^{15} \mathrm{~N}$, increasing from 0.36 (natural abundance) to $>0.7 \mathrm{AP}^{15} \mathrm{~N}$ symbiont $\left(\delta^{15} \mathrm{~N}\right.$ increasing from $\sim 1.0$ to $>914 \%$; Table 2 ). Host tissues were less enriched but still attained a minimum of $0.51 \mathrm{AP}^{15} \mathrm{~N}_{\text {symbiont }}\left(\delta^{15} \mathrm{~N}>404 \%\right.$ ).

There was a significant effect of temperature and depth/ clade, respectively on $\mathrm{AP}^{15} \mathrm{~N}_{\text {symbiont }}$ (SLS; all $p<0.002$; Fig. 1c, d). Within each temperature treatment, Symbiodinium hosted by deep/C7 hosts assimilated more ${ }^{15} \mathrm{~N}$ than their shallow/A3 counterparts. At $26^{\circ} \mathrm{C}$ Symbiodinium from deep/C7 corals were $39 \%$ more enriched in ${ }^{15} \mathrm{~N}$ than shallow/A3 corals from the same treatment (two-tailed $t=$ $-2.4, \mathrm{~d} f=36, p=0.022$; Fig. 1c). Similarly, at $31^{\circ} \mathrm{C}$ Symbiodinium from deep/C7 corals were $37 \%$ more enriched in ${ }^{15} \mathrm{~N}$ than their shallow/A3 counterparts from the same treatment (two-tailed $t=-3.1, \mathrm{~d} f=36, p=0.004$; Fig. 1c).

The effect of temperature on ${ }^{15} \mathrm{~N}$ assimilation was significant within each depth/clade. At $31{ }^{\circ} \mathrm{C}$, deep $\mathrm{AP}^{15} \mathrm{~N}$ symbiont was $31 \%$ more enriched relative to $26^{\circ} \mathrm{C}$ (two-tailed $t=2.72, \mathrm{~d} f=36, p<0.01$; Fig. 1c). Similarly, at $31^{\circ} \mathrm{C}$, shallow/A3 $\mathrm{AP}^{15} \mathrm{~N}_{\text {symbiont }}$ was $32 \%$ more enriched relative to $26{ }^{\circ} \mathrm{C}$ (two-tailed $t=2.06, \mathrm{~d} f=36, p=0.047$; Fig. 1c). $\mathrm{AP}^{15} \mathrm{~N}_{\text {host }}$ did not follow the same pattern (Fig. 1d). Although there was an effect of depth on $\mathrm{AP}^{15} \mathrm{~N}_{\text {host }}$ with deep hosts becoming up to $30 \%$ more enriched relative to shallow hosts (two-tailed $t=-5.6, \mathrm{~d} f=36, p<0.0001$ ), there was no effect of temperature observed (two-tailed $t=$ 1.7, $\mathrm{df}=36, p=0.095$; Fig. 1d). Thus, the difference between symbiont and host ${ }^{15} \mathrm{~N}$ assimilation $\left(\Delta \mathrm{AP}^{15} \mathrm{~N}_{\text {sym- }}\right.$ biont-host) was 69 and $67 \%$ larger at $31^{\circ} \mathrm{C}$ than at $26^{\circ} \mathrm{C}$ for both deep/C7 and shallow/A3 O. faveolata, respectively (Fig. 2c, d).

\section{Discussion}

We exposed $O$. faveolata sourced from the shallow and deep limits of their distribution to an ecologically relevant pre-bleaching warming experiment $\left(+5^{\circ} \mathrm{C}\right.$ over 10 days [33] followed by a snapshot assessment of biogeochemical cycling including determinations of holobiont productivity (NPP), Symbiodinium carbon and nitrogen assimilation, and their subsequent translocation to the host. Previous studies focused on carbon metabolism in scleractinian corals under varied environmental conditions have reported a negative impact of temperature on Symbiodinium photophysiology [10, 38]. In contrast to those works, we observed that Symbiodinium metabolism was increased at sub-bleaching temperatures $\left(31^{\circ} \mathrm{C}\right)$ despite the fact that the $O$. faveolata holobiont had a $60 \%$ reduction in NPP relative to controls (Table 1). At the same time, photosynthesis (as measured by ${ }^{13} \mathrm{C}$ fixation) was constant among deep/C7 corals and increased $14 \%$ among shallow/A3 corals (Fig. 1a). Thus, warming did not impair Symbiodinium photosynthesis but increased holobiont respiration which collectively caused a significant drop in holobiont NPP. Therefore, we conclude that warming induces greater energetic demands on the holobiont before Symbiodinium performance is compromised [16, 39, 40]. Moreover, this increase in respiration was associated with a significant $(15 \%)$ drop in host carbon content, but not in Symbiodinium, suggesting that hosts were bearing the costs of elevated respiration, perhaps by catabolizing lipid reserves. Although the host was still receiving fixed carbon from their symbionts, the overall loss of carbon in host tissues is evidence of passing a tipping point, where the benefits of symbiosis no longer exceeded the costs; a sign of a parasitic interaction [24]. This confirms that during thermal anomalies coral hosts are rapidly taxed by unsustainable respiration that is not offset by photosynthetic benefits. A logical outcome is that a weakened host would be less capable to mitigate oxidative damage induced by a large and healthy symbiont burden [22].

By sampling 2 holobionts adapted to conditions at the extreme ends of the host species' depth distribution we were able to assess the relative importance of light adaptation, Symbiodinium phylotype and temperature on productivity. Relative to deep/C7, shallow/A3 O. faveolata had twice the Symbiodinium density, but similar chla concentrations per cell (Table 1). This suggests that photoprotective mechanisms (e.g., self-shading and host pigments for non-photochemical quenching) were upregulated at shallow depths. In comparison, deep/C7 corals were duller in appearance, and had fewer Symbiodinium with no reduction in chlorophyll per cell, which is indicative of light-limiting conditions [41]. As such, deep/ C7 corals brought to surface light conditions had $34 \%$ more carbon assimilation than shallow/A3 corals owing to more efficient use of light, and showed no response to warming (Fig. 1a). In contrast, warming caused a $14 \%$ increase in carbon assimilation in shallow/A3 corals illustrating that heat can increase photosynthesis even when photoprotective mechanisms are present. Thus, host regulation of photoprotective mechanisms appears to have a stronger influence on symbiont photosynthesis than warming alone. The host's ability to regulate symbiont photosynthesis via protection and inhibition is a plausible negative feedback mechanism for bleaching resistance. Such mechanisms may help to explain the different 


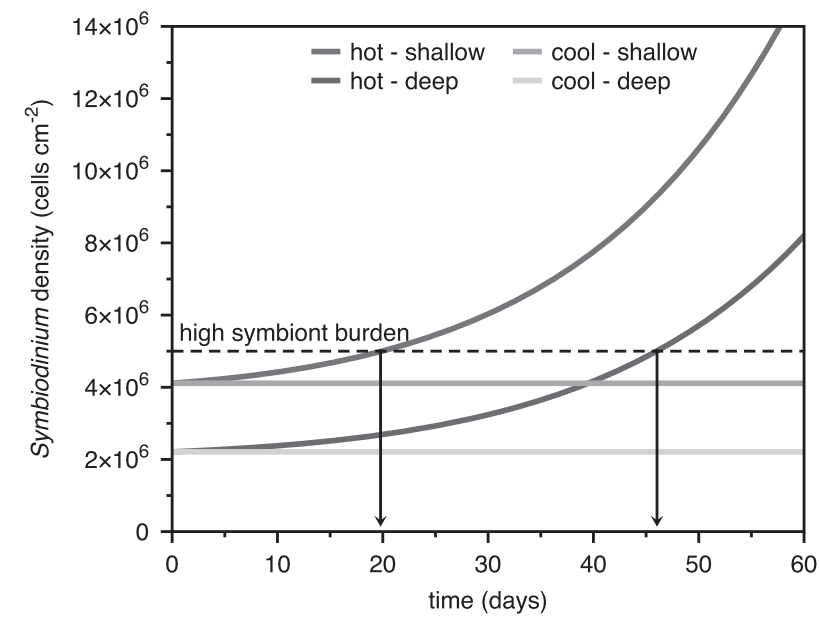

Fig. 3 Hypothetical growth curves of Symbiodinium density based on initial cell densities and final mitotic index (MI) values following 10 days of incubation at elevated temperature and nutrients, for corals adapted to the deep and shallow forereef environment. The "high symbiont burden' threshold is derived from Kemp et al. [38]. For model equations and assumptions, please refer to Supplemental Materials.

bleaching tolerances observed across the diversity of coral holobionts. However, warming had no proportional benefit to the host carbon subsidy, indicating that Symbiodinium either retained their additional carbon or it was respired by the holobiont (Fig. 1b).

In contrast to carbon, Symbiodinium nitrogen assimilation was universally enhanced with warming with no proportional increase in nitrogen obtained by the coral host (Fig. 1c, d). Deep/C7 corals assimilated $>37 \%$ more nitrogen than their shallow conspecifics at both temperatures. This can be attributed to either (1) Symbiodinium identity, which is not mutually exclusive from, or (2) greater photosynthetic efficiency, or (3) different nitrogen exposure histories or (4) a higher nitrogen demand for PSII repair. More importantly, warming and depth/clade were equal in their effect on Symbiodinium nitrogen assimilation. Both deep/C7 and shallow/A3 Symbiodinium assimilated $>31 \%$ more nitrogen when warmed to $31^{\circ} \mathrm{C}$. Although the coral host still benefitted from symbiont nitrogen translocation, there was no proportional increase in translocation due to either warming or depth/clade. Given that nitrate assimilation is an energy intensive process, Symbiodinium effectively lowered their cost by maintaining a fixed subsidy to the host and retaining the surplus assimilated nitrogen [23, 42]. This finding has several major implications. It suggests that when nitrogen is not limiting to primary productivity that warming (1) favors the assimilation of nitrogen and thus, the proliferation of Symbiodinium [29, 31]; (2) nitrate increasingly "evades" host mechanisms (via passive transport, perhaps) to modulate Symbiodinium access to nitrogen, as proposed for organic nitrogen and ammonium [42,
43], and (3) Symbiodinium either translocate a fixed nitrogen subsidy to their host, or hosts are physically or biochemically limited in the amount of nitrogen they can receive. Taken together, these data validate models that predict a synergistic effect of warming and nitrogen on selfish symbiont behavior and coral bleaching [16].

Indeed, the most significant pattern we observed was the increased disparity between host and symbiont carbon and nitrogen assimilation at sub-bleaching temperatures. The difference in resource acquisition between the partners $\left(\Delta \mathrm{AP}^{15} \mathrm{~N}_{\text {symbiont-host }}\right.$ and $\Delta \mathrm{AP}^{13} \mathrm{C}_{\text {symbiont-host }}$ ) showed that the nitrogen gap increased by $>67 \%$ for all holobionts (Fig. 2c, d), and the carbon gap increased by $39 \%$ in shallow/A3 corals at $31{ }^{\circ} \mathrm{C}$ (Fig. 2a). That deep/C7 corals had similar $\Delta \mathrm{AP}^{13} \mathrm{C}_{\text {symbiont-host }}$ at both temperatures could be interpreted as evidence of a stable mutualistic interaction, but we caution that such comparisons between symbiont types are confounded by the physiological adaptations to the deep and shallow forereef. Regardless, these differences were evident after just one day of incubation, and we predict that they would compound over time as Symbiodinium cell division increases.

We simulated such an increase based on the initial cell densities and final mitotic index of our incubated clones, which revealed an interesting pattern (Fig. 3). With just a $1 \%$ higher MI stimulated by heat and abundant resources, cell densities can theoretically increase in shallow corals by $25 \%$ in just 20 days, exceeding 5 million cells $\mathrm{cm}^{-2}$. In deep corals with lower initial symbiont abundance, the time to reach a similar cell density may exceed 45 days. Such densities have been observed in $O$. faveolata prior to bleaching events [38] and may result from the synergistic effects of elevated nutrients and temperature. Indeed, Symbiodinium quickly assimilated nitrate and proportionally fewer organic derivatives were translocated to the host at elevated temperatures. Therefore, during weeks of heat accumulation preceding thermal bleaching events Symbiodinium can sequester significantly more nitrogen and energy than their hosts, which they can subsequently utilize for cell division [29]. A logical next step is to link our observations with long-term changes in symbiont population densities (sensu [22]). Together, the observation of increased holobiont respiration and reduced carbon content (i.e., increased cost to the host) and unchanged translocation (i.e., no net change in cost to the symbiont) and increased resource storage and mitotic index (increased symbiont benefit) is indicative of the mutualism gradually shifting to parasitism [5]. Moreover, these observations validate the assumption that symbiont resource hoarding precedes the proliferation of an unsustainable symbiont burden on the host as predicted by the Wooldridge model.

Although this study is limited to a single coral host $(O$. faveolata), we were able to evaluate the metabolic costs and 
nutritional benefits of hosting Symbiodinium partners that span the continuum from a sensitive mutualist to stresstolerant, opportunistic parasite. S. fitti (ITS2 clade A3) are known for their tolerance of high light and increasing temperature, respectively [6], while being a less beneficial partner to their hosts than clade C Symbiodinium $[5,44])$. Indeed, Symbiodinium within the ITS2 clade $\mathrm{C}$ are generally considered to be more mutualistic as they confer more fitness benefits to their hosts, including carbon [45] and growth limiting nitrogen [26]. C7 is one such mutualist, which is specific to and dominates Orbicella in low-light habitats though is less tolerant of thermal stress [38, 46]. Yet, we observed enhanced symbiont resource uptake (i.e., revenue) with unchanged host translocation (costs), which led to a higher net "profit" in the form of accumulated resources that led to a concomitant increase in cell division (benefits) by both of these symbionts in hospite under thermal stress. At the same time, their hosts sustained a large increase in respiration, which was associated with a reduction in carbon content. Taken together, these observations suggest that warming can create conditions for symbiont parasitism.

Indeed, the functional significance of Symbiodinium diversity in the coral symbiosis is a critically important question to resolve if we are to understand the tolerance, adaptive capacity, and resilience of corals to a warming world [44]. We predict that a truly mutualistic symbiont would confer more resources to their host at a wider range of temperatures, whereas a commensal or parasite would retain more resources, particularly when conditions optimize their fitness $[5,47]$. Here we have observed the latter, where both an opportunistic and stress-tolerant symbiont and a purported low-light adapted mutualist have both become selfish as increasing temperatures favored the retention of resources while simultaneously increasing the respiratory demands of the holobiont. Future work should focus on how these patterns vary across the diversity of host-symbiont interactions, and hosts which vary in their trophic plasticity [9]. In conclusion, we have experimentally shown that warming reduces the benefits of symbiosis when nutrients are non-limiting, which bolsters calls for nutrient pollution to be included with greenhouse gas emissions in climate change mitigation policies that aim to preserve coral reefs $[3,27,48]$.

Acknowledgements We are grateful for the support of the director, manager and staff of the Smithsonian's Carrie Bow Caye Marine Station (CCRE). Special thanks to R. Bowden for technical support with IRMS analyses and SE McIlroy for comments and discussion on the manuscript. Constructive comments from three anonymous reviewers greatly improved the manuscript. This work was supported by a Marine Science Network and MarineGEO Fellowship to DMB and CJF, respectively, the W.M. Keck Foundation to MLF and the Research Grants Council of Hong Kong, Early Career Scheme award (\#789913) to DMB.

\section{Compliance with Ethical Standards}

Conflict of interest The authors declare that they have no conflict of interest.

Open Access This article is licensed under a Creative Commons Attribution-NonCommercial-NoDerivatives 4.0 International License, which permits any non-commercial use, sharing, distribution and reproduction in any medium or format, as long as you give appropriate credit to the original author(s) and the source, and provide a link to the Creative Commons license. You do not have permission under this license to share adapted material derived from this article or parts of it. The images or other third party material in this article are included in the article's Creative Commons license, unless indicated otherwise in a credit line to the material. If material is not included in the article's Creative Commons license and your intended use is not permitted by statutory regulation or exceeds the permitted use, you will need to obtain permission directly from the copyright holder. To view a copy of this license, visit http://creativecommons.org/licenses/by-nc-nd/4.0/.

\section{References}

1. Yellowlees D, Rees TAV, Leggat W. Metabolic interactions between algal symbionts and invertebrate hosts. Plant Cell Environ. 2008;31:679-94.

2. Hughes TP, Barnes ML, Bellwood DR, Cinner JE, Cumming GS, Jackson JBC, et al. Coral reefs in the Anthropocene. Nature. 2017;546:82-90.

3. Vega Thurber RL, Burkepile DE, Fuchs C, Shantz AA, McMinds $\mathrm{R}$, Zaneveld JR. Chronic nutrient enrichment increases prevalence and severity of coral disease and bleaching. Glob Change Biol. 2014;20:544-54.

4. Wooldridge SA. Instability and breakdown of the coral-algae symbiosis upon exceedence of the interglacial $p \mathrm{CO}_{2}$ threshold (>260 ppmv): the 'missing' Earth-System feedback mechanism. Coral Reefs. 2017;36:1025-37.

5. Lesser MP, Stat M, Gates RD. The endosymbiotic dinoflagellates (Symbiodinium sp.) of corals are parasites and mutualists. Coral Reefs. 2013;32:603-11.

6. Pettay DT, Wham DC, Smith RT, Iglesias-Prieto R, Lajeunesse TC. Microbial invasion of the Caribbean by an Indo-Pacific coral zooxanthella. Proc Natl Acad Sci. 2015;112:7513-8.

7. Wooldridge SA. Is the coral-algae symbiosis really 'mutually beneficial' for the partners? BioEssays. 2010;32:615-25.

8. Wooldridge SA. Breakdown of the coral-algae symbiosis: towards formalising a linkage between warm-water bleaching thresholds and the growth rate of the intracellular zooxanthellae. Biogeosciences. 2012;9:8111-39.

9. Grottoli AG, Rodrigues LJ, Palardy JE. Heterotrophic plasticity and resilience in bleached corals. Nature. 2006;440:1186-9.

10. Tchernov D, Gorbunov $M$, de Vargas C, Narayan Yadav S, Milligan A, Häggblom M, et al. Membrane lipids of symbiotic algae are diagnostic of sensitivity to thermal bleaching in corals. Proc Natl Acad Sci. 2004;101:13531-5.

11. Wiedenmann J, D'Angelo C, Smith EG, Hunt AN, Legiret FE, Postle AD, et al. Nutrient enrichment can increase the susceptibility of reef corals to bleaching. Nat Clim Change. 2013;3:160-4.

12. Rowan R, Whitney SM, Fowler A, Yellowlees D. Rubisco in marine symbiotic dinoflagellates: form II enzymes in eukaryotic oxygenic phototrophs encoded by a nuclear multigene family. Plant Cell. 1996;8:539-53.

13. Weis V. Cellular mechanisms of Cnidarian bleaching: stress causes the collapse of symbiosis. J Exp Biol. 2008;211: 3059-66. 
14. Ralph PJ, Gademann R, Larkum AWD. Zooxanthellae expelled from bleached corals at $33^{\circ} \mathrm{C}$ are photosynthetically competent. Mar Ecol Prog Ser. 2001;220:163-8.

15. Strychar KB, Coates M, Sammarco PW. Loss of Symbiodinium from bleached Australian scleractinian corals (Acroporahyacinthus, Favites complanata and Porites solida). Mar Freshw Res. 2004;55:135-44.

16. Wooldridge SA. A new conceptual model for the warm-water breakdown of the coral-algae endosymbiosis. Mar Freshw Res. 2009;60:483.

17. Tansik AL, Fitt WK, Hopkinson BM. External carbonic anhydrase in three Caribbean corals: quantification of activity and role in $\mathrm{CO}_{2}$ uptake. Coral Reefs. 2015;34:703-15.

18. Cunning R, Baker AC. Excess algal symbionts increase the susceptibility of reef corals to bleaching. Nat Clim Change. 2013;3:259-62.

19. Marubini F, Davies P. Nitrate increases zooxanthellae population density and reduces skeletogenesis in corals. Mar Biol. 1996;127:319-28.

20. Fitt WK, McFarland FK, Warner ME, Chilcoat GC. Seasonal patterns of tissue biomass and densities of symbiotic dinoflagellates in reef corals and relation to coral bleaching. Limnol Ocean. 2000;45:677-85.

21. Chen C, Wang J, Fang L. Fluctuating algal symbiont communities in Acropora palifera (Scleractinia: Acroporidae) from Taiwan. Mar Ecol Prog Ser. 2005;295:113-21.

22. Cunning R, Baker AC. Not just who, but how many: the importance of partner abundance in reef coral symbioses. Front Microbiol. 2014;5:400.

23. Douglas AE. Conflict, cheats and the persistence of symbioses. New Phytol. 2008;177:849-58.

24. Johnson NC, Graham JH, Smith FA. Functioning of mycorrhizal associations along the mutualism-parasitism continuum. New Phytol. 1997;135:575-85.

25. Knowlton N, Rohwer F. Multispecies microbial mutualisms on coral reefs: the host as a habitat. Am Nat. 2003;162:S51-62.

26. Baker DM, Weigt L, Fogel M, Knowlton N. Ancient DNA from coral-hosted Symbiodinium reveal a static mutualism over the last 172 years. PLoS ONE. 2013;8:e55057.

27. Wooldridge SA, Done TJ, Thomas CR, Gordon II, Marshall PA, Jones RN. Safeguarding coastal coral communities on the central Great Barrier Reef (Australia) against climate change: realizable local and global actions. Clim Change. 2012;112:945-61.

28. Cunning R, Muller EB, Gates RD \& Nisbet RM. A dynamic bioenergetic model for coral-Symbiodinium symbioses and coral bleaching as an alternate stable state. J Theor Biol. 2017;431:49-62..

29. Fagoonee I, Wilson H, Hassell M, Turner JR. The dynamics of zooxanthellae populations: a long-term study in the field. Science. 1999;283:843-5.

30. Hoegh-Guldberg O, Smith GJ. Influence of the population density of zooxanthellae and supply of ammonium on the biomass and metabolic characteristics of the reef corals Seriatopora hystrix and Stylophora pistillata. Mar Ecol Prog Ser. 1989;57:173-86.

31. Nordemar I, Nystrom M, Dizon R. Effects of elevated seawater temperature and nitrate enrichment on the branching coral Porites cylindrica in the absence of particulate food. Mar Biol. 2003;142:669-77.

32. Tomasik T, Sander F. Effects of eutrophication on reef-building corals I. Growth rate of the reef-building coral Montastrea annularis. Mar Biol. 1985;87:143-55.
33. Aronson RA, Precht WP, Toscano MT, Koltes KK. The 1998 bleaching event and its aftermath on a coral reef in Belize. Mar Biol. 2002;141:435-47.

34. Warner ME, Lajeunesse TC, Robison JD, Thur RM. The ecological distribution and comparative photobiology of symbiotic dinoflagellates from reef corals in Belize: potential implications for coral bleaching. Limnol Ocean. 2006;51:1887-97.

35. Jeffrey SW, Humphrey GF. New spectrophotometry equations for determining chlorophylls $\mathrm{a}, \mathrm{b}, \mathrm{c} 1$ and $\mathrm{c} 2$ in higher plants, algae and natural phytoplankton. Biochim und Physiol der Pflanz. $1975 ; 167: 191-4$

36. LaJeunesse T. Diversity and community structure of symbiotic dinoflagellates from Caribbean coral reefs. Mar Biol. 2002;141:387-400.

37. Franklin EC, et al. GeoSymbio: a hybrid, cloud-based web application of global geospatial bioinformatics and ecoinformatics for Symbiodinium-host symbioses. Mol Ecol Resour. 2012;12:369-73.

38. Kemp DW, Hernandez-Pech X, Iglesias-Prieto R, Fitt WK, Schmidt GW. Community dynamics and physiology of Symbiodinium spp. before, during, and after a coral bleaching event. Limnol Oceanogr. 2014;59:788-97.

39. Al-Horani FA. Effects of changing seawater temperature on photosynthesis and calcification in the scleractinian coral Galaxea fascicularis, measured with $\mathrm{O}_{2}, \mathrm{Ca}^{2+}$ and $\mathrm{pH}$ microsensors. Sci Mar. 2005;69:347-54.

40. Coles SL, Jokiel PL. Effects of temperature on photosynthesis and respiration in hermatypic corals. Mar Biol. 1977;43:209-16.

41. Falkowski PG, Dubinsky Z, Muscatine L, McCloskey L. Population control in symbiotic corals. BioScience. 1993;43: 606-11.

42. Ezzat L, Maguer JF, Grover R, Ferrier-Pagès C. New insights into carbon acquisition and exchanges within the coral-dinoflagellate symbiosis under $\mathrm{NH}_{4}{ }^{+}$and $\mathrm{NO}_{3}{ }^{-}$supply. Proc Roy Soc B. 2015;282:20150610.

43. Grover R, Maguer J-F, Allemand D, Ferrier-Pages C. Uptake of dissolved free amino acids by the scleractinian coral Stylophora pistillata. J Exp Biol. 2008;211:860-5.

44. Stat M, Morris E, Gates RD. Functional diversity in coral-dinoflagellate symbiosis. Proc Natl Acad Sci. 2008;105:9256-61.

45. Cantin NE, van Oppen MJH, Willis BL, Mieog JC, Negri AP. Juvenile corals can acquire more carbon from high-performance algal symbionts. Coral Reefs. 2009;28:405-14.

46. Kennedy EV, et al. Symbiodinium biogeography tracks environmental patterns rather than host genetics in a key Caribbean reef-builder. Orbicella Annu Proc Biol Sci. 2016;283: 20161938.

47. Grégoire V, Schmacka F, Coffroth MA, Karsten U. Photophysiological and thermal tolerance of various genotypes of the coral endosymbiont Symbiodinium sp. (Dinophyceae). J Appl Phycol. 2017;275:2273.

48. Zaneveld JR, Burkepile DE, Shantz AA, Pritchard CE, McMinds $\mathrm{R}$, Payet JP, et al. Overfishing and nutrient pollution interact with temperature to disrupt coral reefs down to microbial scales. Nat Commun. 2016;7:11833.

49 Mcllroy SE, Coffroth MA. Coral ontogeny affects early symbiont acquisition in laboratory-reared recruits. Coral Reefs. 2017;36:927-932 